\title{
Prostitution laws failing sex workers: CPHA
}

$\mathrm{S}$ elling sex isn't illegal in Canada, but a new law that criminalizes its purchase is putting sex workers in harm's way, warns the Canadian Public Health Association (CPHA).

Canada's existing prostitution laws "do not address the root causes and pathways that lead many people into the sex industry, nor do they address the workplace health and safety concerns of the sex workers," the association levelled in a December position paper. Instead, the sex industry should be regulated like any other business under workplace health, safety and antidiscrimination laws - not the Criminal Code.

"This isn't a legal issue, this is a public health and safety issue and we should treat it as such," says CPHA Executive Director Ian Culbert. Recent experience shows that any other approach "ends up being a very moral discussion, as opposed to looking at the evidence, looking at what harms are being done, and minimizing those harms as much as possible."

In 2013, the Supreme Court of Canada struck down three federal laws that prohibited sex workers from living in a brothel or communicating for the purposes of prostitution, and third parties from living on the proceeds of sex work. It unanimously ruled these laws violated sex workers' charter rights to life, liberty and security of the person because they barred sex workers from working safely indoors, screening clients or hiring security.

The new Protection of Communities and Exploited Persons Act enacted by Parliament Nov. 4 focuses more on pimps and clients of sex workers. It criminalizes the purchase of sex, but still includes restrictions on communicating in public and indirect profit from sex work - provisions some sex workers and legal experts say rebuild the barriers knocked down by the Supreme Court. It's a model Sweden pioneered in 1999, and one CPHA says has ultimately failed.

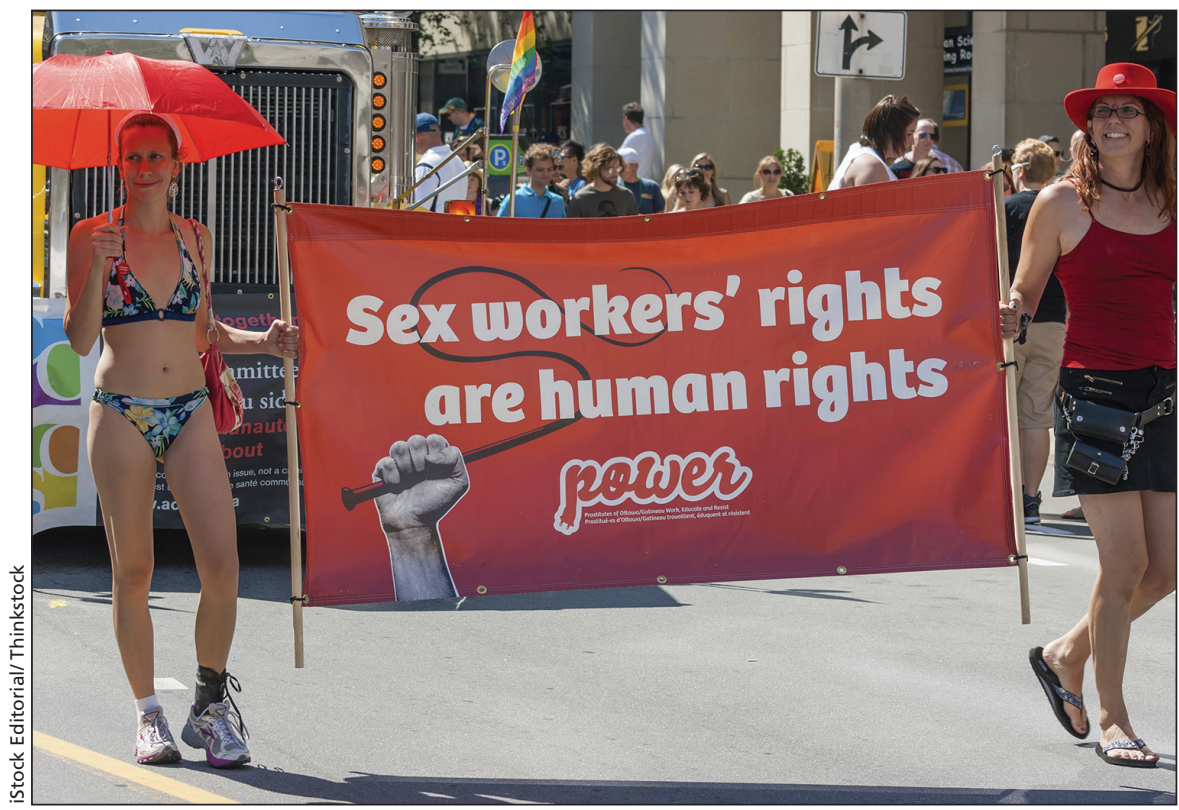

The sex trade should be regulated, not criminalized, to protect the health and safety of workers, urges the Canadian Public Health Association in a new report.

"We looked at all the evidence that was available and we didn't see a significant decrease in demand around the purchase of sex in countries where the Nordic model has been adopted," says Culbert. "But we did see that it continues to place the sex workers' safety at risk."

According to the CPHA, sex workers in Sweden experienced increased risk of violence, police scrutiny and discrimination, difficulty finding housing, and reluctance from clients to help report crimes. In comparison, countries such as New Zealand which regulate the sex trade under workplace health, safety and antidiscrimination laws report higher condom use, lower prevalence of sexually transmitted infections, and increased access to sexual health services. Even so, the concept of applying a harm reduction approach to the sex industry remains controversial.

"It only makes sense if we are prepared to acknowledge that for many women the act of prostitution itself causes grave physical and psychological harm," says Janine Benedet, direc- tor of The Centre for Feminist Legal Studies at the University of British Columbia in Vancouver. "In the same way, we don't suggest that harm reduction is the right approach to domestic violence or sexual harassment; we understand those to be practices of sex discrimination and inequality."

She also argues that CPHA misrepresents "substantial support for the Nordic model within Canada, and the Swedish government's own evaluation of its laws ... as being very successful." For example, "there's mention of a letter signed by 300 academics opposing Canada's approach, but no mention of a letter signed by 800 people supporting it."

Others contend that adopting the New Zealand model in Canada would give sex workers more control over sexual exchanges, decrease exploitation and violence, and reduce the risk of disease transmission.

"Emphasis should be put on improving working conditions and addressing the power imbalances that sometimes happen between business owners and workers," says Nikki Thomas, a 
Toronto-based escort and former executive director of the Sex Professionals of Canada. However, any new approach should be driven by sex workers, she says. "If it isn't fully engaging us from the start then it's basically going to be ignored."

According to Katrina Pacey, executive director of the Vancouver-based non-profit Pivot Legal Society, the sex industry may not actually require additional regulation above and beyond existing business law.

"The things we're actually worried about, like human trafficking, sexual exploitation of children, assault, extortion, violence, coercion and exploitation - all of those things are already addressed in our Criminal Code," she says. "You could remove provisions harming sex workers and have those other provisions provide all the protections they need, with fuller access and less discrimination." - Lauren Vogel, CMAJ

CMAJ 2015. DOI:10.1503/cmaj.109-4968 